\title{
Development of New Waste Forms to Immobilize lodine-129 Released from a Spent Fuel Reprocessing Plant
}

\section{Hiromi Tanabe ${ }^{1, a}$, Tomofumi Sakuragi ${ }^{1, b}$, Kenji Yamaguchi $^{1, \mathrm{c}}$, Taemi Sato ${ }^{1, \mathrm{~d}}$, and Hitoshi Owada ${ }^{1, e}$}

${ }^{1}$ Radioactive Waste Management Funding and Research Center, 1-15-7, Tsukishima, Chuo-ku, Tokyo, 104-0052, Japan

atanabe.hiromi@rwmc.or.jp, bsakuragi@rwmc.or.jp, cyamaguchi@rwmc.or.jp,

dtaemi.sato@rwmc.or.jp, eowada@rwmc.or.jp

Keywords: I-129, iodine filter, TRU waste, reprocessing plant, synthetic rock technique, high-performance cement technique, BPI vitrification technique

\begin{abstract}
I-129 is a very long-lived radionuclide that is released to an off-gas stream when spent fuels are dissolved at a reprocessing plant. An iodine filter can capture I-129 in the form of AgI. However, because AgI is unstable under the reducing conditions of a geological repository and I-129 has a very long half-life, I-129 can migrate to the biosphere. These characteristics make I-129 a key radionuclide for the safety assessment of a geological disposal of radioactive wastes generated from a reprocessing plant (TRU wastes). To improve disposal safety, several new waste forms have been developed to confine I-129 for a very long period in order to reduce the leaching of I-129 from radioactive wastes. These new waste forms have technical objectives of solidifying more than $95 \%$ of I-129 into the waste form and achieving a leaching rate of less than $10^{-5} / \mathrm{y}$. Several iodine immobilization techniques have been examined. This paper presents experimental results concerning the treatment process, leaching behavior, modeling, and related elements of these immobilization techniques.
\end{abstract}

\section{Introduction}

At a reprocessing plant, an iodine filter with silver nitrate $\left(\mathrm{AgNO}_{3}\right)$ impregnated on an alumina base material (silver quantity of about $10 \mathrm{wt} \%$ ) is used to adsorb I-129 in the chemical form of silver iodide $(\mathrm{AgI})$ or silver iodate $\left(\mathrm{AgIO}_{3}\right)$, where the adsorbed quantity of iodine on the iodine filter is set to $6.2 \mathrm{wt} \%$ on average. Because $\mathrm{AgI}$ and $\mathrm{AgIO}_{3}$ are dissociated into $\mathrm{I}^{-}$or $\mathrm{IO}_{3}{ }^{-}$ions in the groundwater under the reducing conditions of disposal, instantaneous release is assumed to occur. These ions are highly soluble in groundwater, and it cannot be assumed that their radioactivity will be attenuated by the delay imposed by artificial barriers. Therefore, their migration to the biosphere depends mostly on natural barrier conditions such as the groundwater flow rate. A report concerning the concept and the safety evaluation of a geological disposal of radioactive wastes generated from a reprocessing plant including a spent iodine filter and from a mixed oxide (MOX) fuel fabrication plant (the "TRU report") has stated that I-129 is the most important of the key 
radionuclides $[1,2]$.

Attenuation by confinement in a container is not expected to be a practical way to reduce the radiation dose of the I-129 because of its very long half-life of 15.7 million years. However, reducing the peak radiation dose by solidifying I-129 into a substance that shows good long-term confinement performance of I-129 and would allow I-129 to be released gradually over a long period, may be a more practical solution, in our consideration.

\section{Development objectives}

Confinement performance of solidified substances. The radionuclides migration analysis model in the TRU report [2] can be used to calculate the effects of the solidified substance's long-term confinement performance upon radiation dose, for use in evaluation. Table 1 shows the main parameters and codes used in the model's calculations.

Table 1 Main parameters and codes used in the calculation

\begin{tabular}{|c|c|c|}
\hline $\begin{array}{r}\text { Confinement Performance } \\
\text { (set as a leaching period) }\end{array}$ & \multicolumn{2}{|c|}{ Instantaneous release, $10^{4}, 10^{5}$, and $10^{6}$ years } \\
\hline \multirow[t]{2}{*}{ Groundwater transmissivity coefficient } & \multirow[t]{2}{*}{$\begin{array}{l}\text { Log-normal distribution } \\
\text { mean: }-0.99 \\
\text { standard deviation: } 1.07\end{array}$} & $\begin{array}{l}\text { Reference case } \\
\text { maximum: } 10^{-7} \mathrm{~m}^{2} / \mathrm{s} \\
\text { minimum: } 10^{-13} \mathrm{~m}^{2} / \mathrm{s} \\
\end{array}$ \\
\hline & & $\begin{array}{l}\text { Variation case } \\
\text { maximum value: } 10^{-6} \mathrm{~m}^{2} / \mathrm{s} \\
\text { minimum value: } 10^{-12} \mathrm{~m}^{2} / \mathrm{s}\end{array}$ \\
\hline Base rock & \multicolumn{2}{|l|}{ Granite } \\
\hline Depth & \multicolumn{2}{|l|}{$1,000 \mathrm{~m}$} \\
\hline Groundwater chemical conditions & \multicolumn{2}{|c|}{ High $\mathrm{pH}$, precipitating groundwater } \\
\hline Groundwater migration distance & \multicolumn{2}{|l|}{$100 \mathrm{~m}$} \\
\hline Biosphere model & \multicolumn{2}{|l|}{ River water } \\
\hline Solubility & \multicolumn{2}{|l|}{ Soluble } \\
\hline \multirow[t]{3}{*}{ Distribution coefficient } & \multicolumn{2}{|c|}{ Cement mortar: $0.000125 \mathrm{~m}^{3} / \mathrm{kg}$} \\
\hline & \multicolumn{2}{|c|}{ Compressed bentonite: $0 \mathrm{~m}^{3} / \mathrm{kg}$} \\
\hline & \multicolumn{2}{|l|}{ Rock: $0.0001 \mathrm{~m}^{3} / \mathrm{kg}$} \\
\hline \multirow[t]{2}{*}{ Effective diffusion coefficient } & \multicolumn{2}{|c|}{ Compressed bentonite: $4 \times 10^{-11} \mathrm{~m}^{2} / \mathrm{s}$} \\
\hline & \multicolumn{2}{|l|}{ Granite: $3 \times 10^{-12} \mathrm{~m}^{2} / \mathrm{s}$} \\
\hline \multirow[t]{2}{*}{ Calculation code } & \multicolumn{2}{|l|}{ Engineered barrier: FRONT $^{* 1}$} \\
\hline & \multicolumn{2}{|l|}{ Natural barrier: CRACK $^{* 2}$} \\
\hline
\end{tabular}

*1; 1-dimensional migration calculation code

*2; 2-dimensional migration calculation code 
Fig. 1 shows the results of this analysis. The peak radiation dose is larger for the variation case of transmissivity than for the reference case. In both cases, when the leaching period exceeds $10^{5}$ years, the effect of the leaching period becomes dominant. For the confinement performance of the solidified substance, this result indicates that if the leaching period exceeds $10^{4}$ years, then reducing $\mathrm{I}-129$ in the release

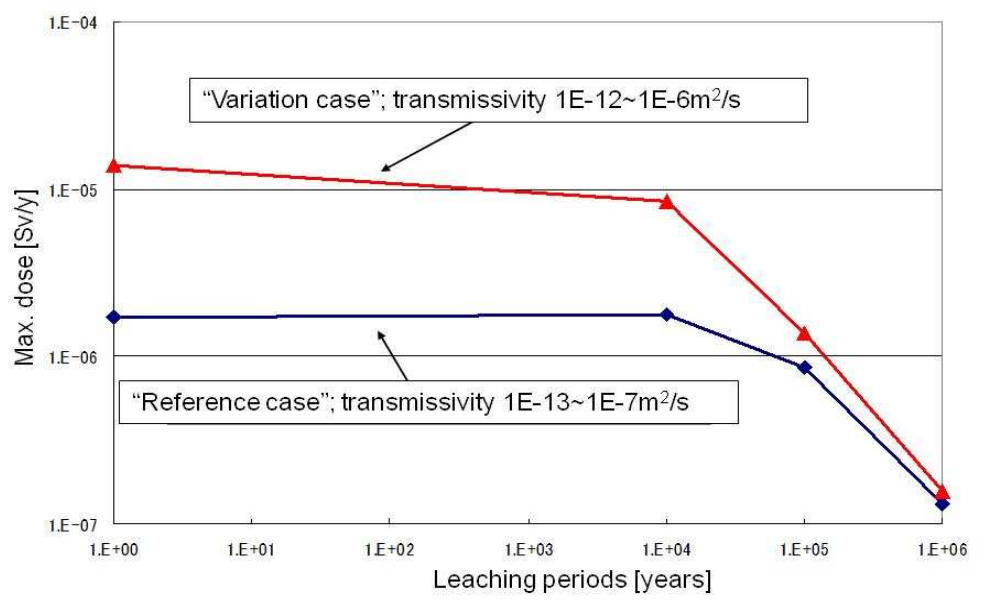

Fig. 1 I-129 max. dose vs. leaching period with different transmissivity flux from the solidified substance will affects the release flux to the biosphere. This effect is greater in the variation case, which has a larger transmissivity coefficient, than in the reference case. If the leaching period is $10^{5}$ years in the variation case, the peak radiation dose is reduced by about a factor of 10 and becomes lower than the peak radiation dose for the case of instantaneous release in the reference case. Based on this analysis, we set the confinement performance objective of the solidified substance to $10^{5}$ years or longer.

Recovery efficiency at the solidification treatment process. Even if iodine is confined in a solidified substance with superior confinement performance, as described above, some amount of I-129 may not be confined in the solidified substance. Because such unconfined I-129 is considered as instantaneous release, as much of $\mathrm{I}-129$ as possible must be recovered by confinement in a solidified substance. A recovery efficiency of $95 \%$ or higher was set as an objective in order not to affect the objective value set for confinement performance.

\section{Development of immobilization techniques}

Synthetic rock technique [3-6].

Outline and principle. The synthetic rock technique is a solidification treatment technique in which I-129 is processed by Hot Isostatic Pressing (HIP) without being desorbed from the spent iodine filter. The alumina adsorbent base material is compounded into a dense solidified substance (synthetic rock), and I-129 is physically confined in the alumina matrix.

Process flow and treatment conditions. I-129 is treated by HIP processing at a pressure of $175 \mathrm{MPa}$ and a temperature of $1473 \mathrm{~K}$ for 3 hours. As a result, iodine can be confirmed to be physically confined in a dense alumina matrix. As a pretreatment for HIP, unused $\mathrm{AgNO}_{3}$ and $\mathrm{AgIO}_{3}$, which can inhibit the matrix densification in the HIP treatment, undergo heat treatment to be transformed into Ag and AgI, respectively. Next, the spent iodine filter is filled into a stainless steel capsule, and the capsule undergoes vacuum degassing and is sealed. Then, HIP treatment is conducted to make the synthetic rock solidified substance. This treatment can lower the probability 
of I-129 release during treatment because the treatment is carried out without desorbing I-129 from the spent iodine filter. Fig. 2 shows the treatment flow.

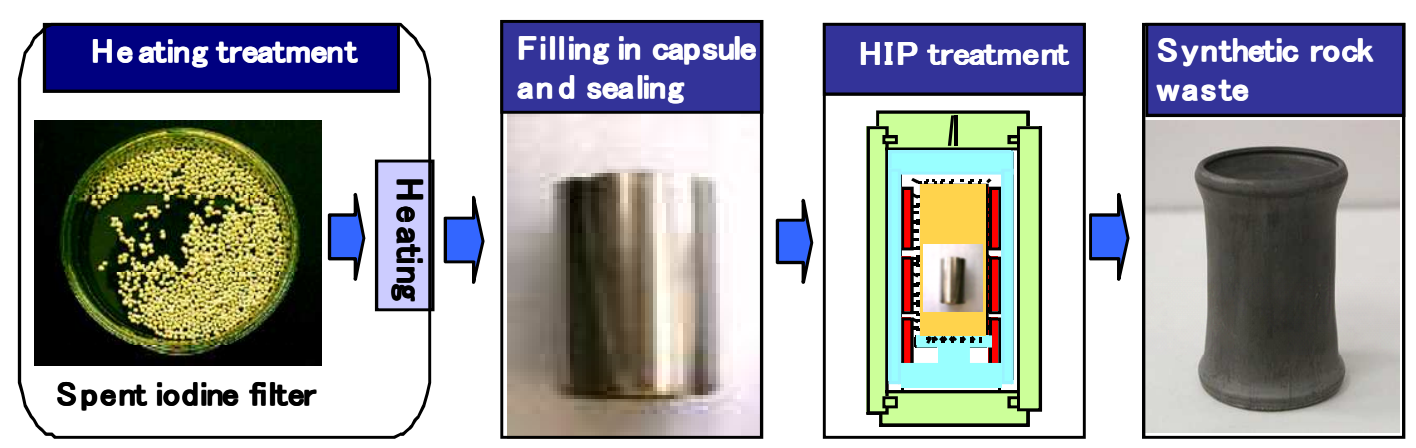

Fig. 2 Flow of synthetic rock treatment by the HIP method

Characteristics of solidified substance. The solidified cross-sectional observation and SEM observation $(\times 1,000)$ of the prepared solidified substances showed that there were no cracks in the solidified substance. Gross porosity obtained from the absolute specific gravity $\left(4.38 \mathrm{~g} / \mathrm{cm}^{3}\right)$ and the bulk density $\left(4.05 \mathrm{~g} / \mathrm{cm}^{3}\right)$ was about $8 \%$ of which open porosity of the cubic piece $(10 \mathrm{~mm} \mathrm{x}$ $10 \mathrm{~mm} \times 10 \mathrm{~mm}$ ) measured by mercury intrusion porosimetry was $1-3 \%$. This matrix was a stable corundum $\left(\alpha-\mathrm{Al}_{2} \mathrm{O}_{3}\right)$ with a uniform distribution of iodine, which was immobilized in the chemical form of AgI. The uniaxial compressive strength of the solidified substance was 1.2 GPa.

To evaluate the I-129 retention capacity of the synthetic rock, leaching tests into solutions that simulated the geological disposal conditions were conducted. Table 2 shows the leaching conditions for the tests and Fig. 3 shows the change in amount of iodine and aluminum leached versus time. The amount of iodine leached tends to decrease gradually with time. This decrease becomes particularly dominant at 200-300 days after the start of leaching, or later.

To evaluate the long-term release behavior of I-129 from the synthetic rock, tests were conducted to confirm the dominant release process among three possible release mechanisms: matrix dissolution, AgI dissolution, and pore diffusion.

Matrix dissolution: the corundum, a component of the solidified substance, is chemically stable; however, under high-alkaline conditions, i.e. the reference disposal environment in the TRU report $[1,2]$, the solubility becomes larger than under neutral conditions. Accordingly, data concerning the solubility and dissolution rate of the synthetic rock versus $\mathrm{pH}$ were acquired, assuming disposal conditions and using $\mathrm{NaOH}$ and $\mathrm{Ca}(\mathrm{OH})_{2}$ as $\mathrm{pH}$ adjusters. The results, which are shown in Fig. 4 and Fig. 5, can be described by the following equation for the matrix dissolution rate in free water.

$$
\mathrm{R}(\mathrm{Al})=\mathrm{k}_{\mathrm{Al}}\left(1-\mathrm{C} / \mathrm{C}_{\mathrm{M}}\right)
$$

where $\mathrm{R}(\mathrm{Al})$ : normalized aluminum dissolution rate $\left[\mathrm{mol} / \mathrm{cm}^{2} / \mathrm{d}\right]$,

$\mathrm{C}$ : aluminum concentration $[\mathrm{mol} / \mathrm{L}]$, 
$\mathrm{C}_{\mathrm{M}}$ : aluminum saturated solubility [mol/L],

$\mathrm{k}_{\mathrm{Al}}$ : rate constant $\left(\mathrm{k}_{\mathrm{Al}}=1.09 \times 10^{-7} \times\left[\mathrm{H}^{+}\right]^{-0.309} \times \exp (-27,200 / \mathrm{RT})\left[\mathrm{mol} / \mathrm{cm}^{2} / \mathrm{d}\right]\right.$,

$\left[\mathrm{H}^{+}\right]$: hydrogen ion concentration $[\mathrm{mol} / \mathrm{L}]$,

$\mathrm{R}$ : gas constant $[\mathrm{J} / \mathrm{K} / \mathrm{mol}]$, $\mathrm{T}$ : temperature $[\mathrm{K}]$

Table 2 Test conditions for long-term leaching

\begin{tabular}{|l|l||l|}
\hline Specimen size & $\mathrm{mm}$ & $20 \times 20 \times 20$ \\
\hline $\mathrm{pH}$ of solution & & $\begin{array}{l}12.5 \\
{\left[\mathrm{by} \mathrm{Ca}(\mathrm{OH})_{2}\right]}\end{array}$ \\
\hline Temperature & $\mathrm{K}$ & 308 \\
\hline Reducing agent & & $\mathrm{Na}_{2} \mathrm{~S}$ \\
\hline Concentration & $\mathrm{mol} / \mathrm{dm}^{3}$ & $3 \times 10^{-3}$ \\
\hline $\begin{array}{l}\text { Solid liquid ratio } \\
(\mathrm{S} / \mathrm{V})\end{array}$ & $\mathrm{cm}^{-1}$ & 0.1 \\
\hline $\begin{array}{l}\mathrm{O}_{2} \text { concentration } \\
\text { in gas phase }\end{array}$ & $\mathrm{ppm}$ & $<1$ \\
\hline
\end{tabular}

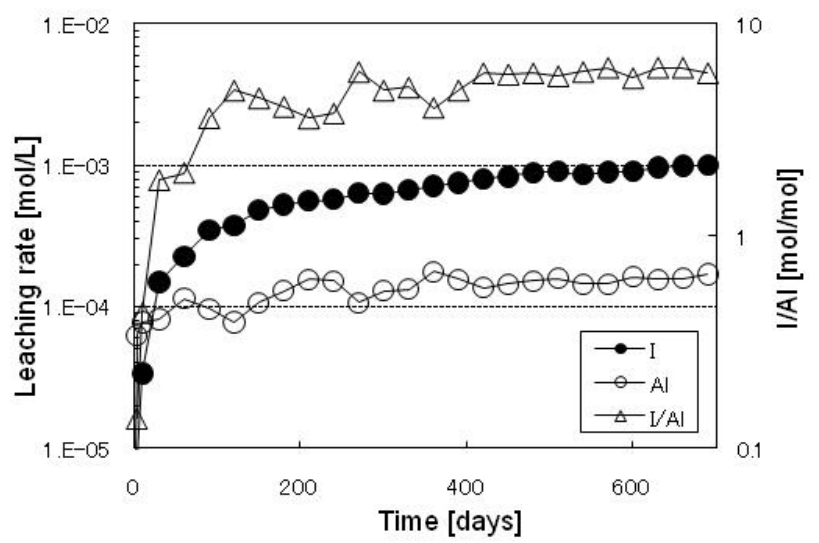

Fig. 3 Results of leaching test (amount of iodine and aluminum leached)

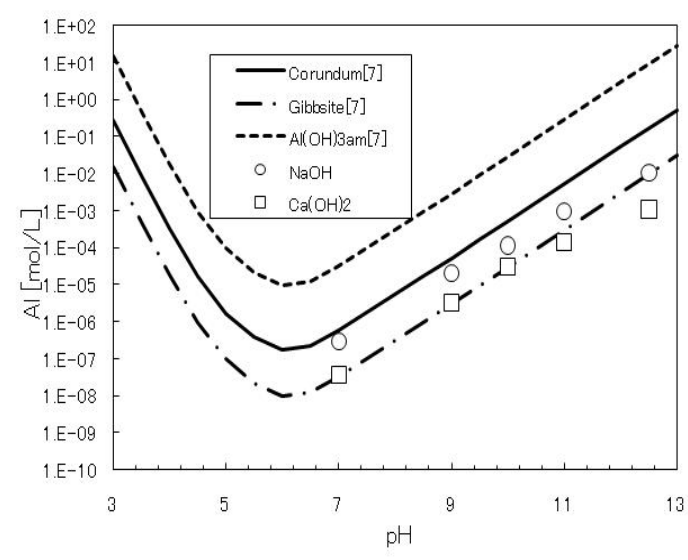

Fig. 4 Solubility data of synthetic rock substance matrix

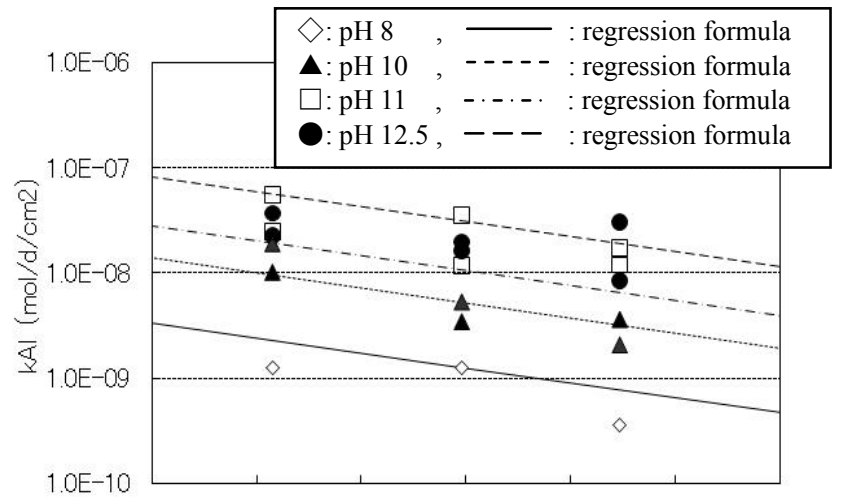

2.8E-03 2.9E-03 3.0E-03 3.1E-03 3.2E-03 3.3E-03 3.4E-03 $1 / \top(1 / K)$

Fig. 5 Results of solubility test of synthetic rock substance matrix

According to Eq. 1, the matrix dissolution rate at $\mathrm{pH} 12.5$ was estimated to be $9.7 \times 10^{-7}$ $\mathrm{g}-\mathrm{Al} / \mathrm{cm}^{2} / \mathrm{d}$ and was converted into the iodine dissolution rate to be $1.5 \times 10^{-7} \mathrm{~g}-\mathrm{I} / \mathrm{cm}^{2} / \mathrm{d}$ using the assumption of the congruent dissolution of the matrix.

AgI dissolution: AgI can elute $\mathrm{I}^{-}$by a reducing reaction $\left(\mathrm{AgI}+\mathrm{e}^{-} \rightarrow \mathrm{Ag}^{0}+\mathrm{I}^{-}\right)$using $\mathrm{HS}^{-}$, which is supposed to be a reducing species in the groundwater at the disposal environment, and also by a chemical reaction $\left(2 \mathrm{AgI}+\mathrm{HS}^{-}=\mathrm{Ag}_{2} \mathrm{~S}+2 \mathrm{I}^{-}+\mathrm{H}^{+}\right)$. Accordingly, a dissolution test of $\mathrm{AgI}$ in $\mathrm{Na}_{2} \mathrm{~S}$ solution was conducted. The results showed that, under the presence of HS- AgI dissolution progressed rapidly as a result of a chemical reaction using $\mathrm{Ag}_{2} \mathrm{~S}$ precipitation and that an $\mathrm{Ag}_{2} \mathrm{~S}$ dissolution-precipitation equilibrium was almost reached within a reaction time of several days or shorter. At this point, the AgI dissolution rate at $\mathrm{pH} 12.5$ was estimated to be $4.9 \times 10^{-4} \mathrm{~g}-\mathrm{I} / \mathrm{cm}^{2} / \mathrm{d}$, 
which is faster than the matrix dissolution rate stated above.

Pore diffusion: to obtain estimates of the diffusion coefficient, permeation diffusion tests were conducted on a solidified substance test piece of $1 \mathrm{~mm}$ thickness using the $\mathrm{Cs}^{+}$ion. The result was that no $\mathrm{Cs}^{+}$permeation was observed during the test period of 270 days. This lack of permeation is considered to result from the low open porosity of only 1-3\% and the low continuity of the pores. The low continuity can be inferred from the fact that permeation range was limited to a shallow surface area in the test of permeation from the solidified substance surface using the internal diffusion method.

According to these test results, the release of iodine from the synthetic rock is expected to occur in a process like this: the matrix within the solidified substance dissolves in a solution, then the $\mathrm{AgI}$ that comes into contact with the solution dissolves quickly, and iodine is released. It is considered possible that the pores on the surface of the solidified substance may affect the permeation of the solution into the matrix and the release of iodine. However, because the open porosity was low and no predominant pores were found in cross-sectional observation, this effect is considered to be small. Even though iodine and aluminum were dissolved congruently, Fig. 3 shows the I/Al release ratio to be several tens times the stoichiometrical ratio of approximately 0.15 , as calculated from the composition of the sampled solidified substance. However, because the aluminum concentration measured in the leaching test was lower than the concentration in the acquired solubility data with the powdered solidified substance, this difference is assumed to be caused by the precipitation of aluminum as a secondary mineral. On this assumption, the release ratio was corrected to be approximately 0.9 which is still higher than the stoichiometrical ratio. If the solubility calculated using the PHREEQC with thermodynamic data of corundum [7] shown in Fig. 4 is used, the I/Al release ratio is corrected to be approximately 0.01 which is much lower than the stoichiometrical ratio.

The long-term performance of the synthetic rock solidified substance was evaluated by calculating the life of the solidified substance, assuming that the matrix instantaneously reaches solubility equilibrium with the groundwater in a cement environment of $\mathrm{pH} 12.5$. The solubility data for $\mathrm{Ca}(\mathrm{OH})_{2}$ in Fig. 4 show that this environment is a severe one for the synthetic rock. The aluminum concentration of the groundwater was set to 0 for the calculation. For hydraulic conditions, the hydraulic gradient was set to $1 \%$ and the permeability coefficient set to $10^{-8} \mathrm{~m} / \mathrm{s}$, based on the values in the TRU Report [1]. The result of the calculation using the acquired solubility data is a life of $10^{5}$ years or longer for the solidified substance.

\section{High-performance cement technique [8,9].}

Outline and principle. The high-performance cement technique is a solidification method that can immobilize $\mathrm{IO}_{3}{ }^{-}$with a certain designed special cement material. The cement is minerally enriched with the calcium-aluminate ferrites, i.e. ettringite (AFt) and monosulfate (AFm), and has an oxyanion substitution ability. AFt has a needle crystalline structure with a hexagonal cross-section and is described by the chemical formula $\left[\mathrm{Ca}_{6}\left(\mathrm{Al}(\mathrm{OH})_{6}\right)_{2} \cdot 24 \mathrm{H}_{2} \mathrm{O}\right]\left(\mathrm{SO}_{4}\right)_{3} \cdot 2 \mathrm{H}_{2} \mathrm{O}$, and 
AFm is a hexagonal crystal described by the chemical formula $\left[\mathrm{Ca}_{2}\left(\mathrm{Al}(\mathrm{OH})_{6}\right]_{2}\left(\mathrm{SO}_{4}\right) \cdot 6 \mathrm{H}_{2} \mathrm{O}\right.$. The chemical formulas show a positive-charged column structure for $\mathrm{AFt}$ and a laminated plate structure for $\mathrm{AFm} . \mathrm{SO}_{4}{ }^{2-}$ and hydrated water are located in channels between the columns and plates. It is known that $\mathrm{SO}_{4}{ }^{2-}$ in the structure can be replaced by a different anion, such as $\mathrm{OH}^{-}$or $\mathrm{CO}_{3}{ }^{2-}$. After desorption from a spent iodine filter by a reductive reaction, liquid-phase $\mathrm{I}^{-}(\mathrm{I}-129)$ is formed as the oxyanion $\mathrm{IO}_{3}{ }^{-}$by an oxidative reaction. The oxyanion easily substitute for $\mathrm{SO}_{4}{ }^{2-}$ of $\mathrm{AFt}$ and AFm. Aft and AFm are known as stable minerals in natural conditions.

Process flow and conditions. The process flow of high-performance cement solidification is shown in Fig. 6. Iodine-129 in the chemical form of AgI impregnated in the spent iodine filter is dissolved into the chemical form of $\mathrm{I}^{-}$by a reducing reaction using $\mathrm{Na}_{2} \mathrm{~S}$. Then all of the $\mathrm{I}^{-}$is oxidized to $\mathrm{IO}_{3}{ }^{-}$by ozone gas scrubbing. Finally, the $\mathrm{IO}_{3}^{-}$solution is mixed with the high-performance cement material, which contains large amounts of AFt and AFm.

\section{Characteristics of solidified substance.}

The physical properties and workability of the high-performance cement material are shown in Table 3. These properties and workability are comparable to those of a

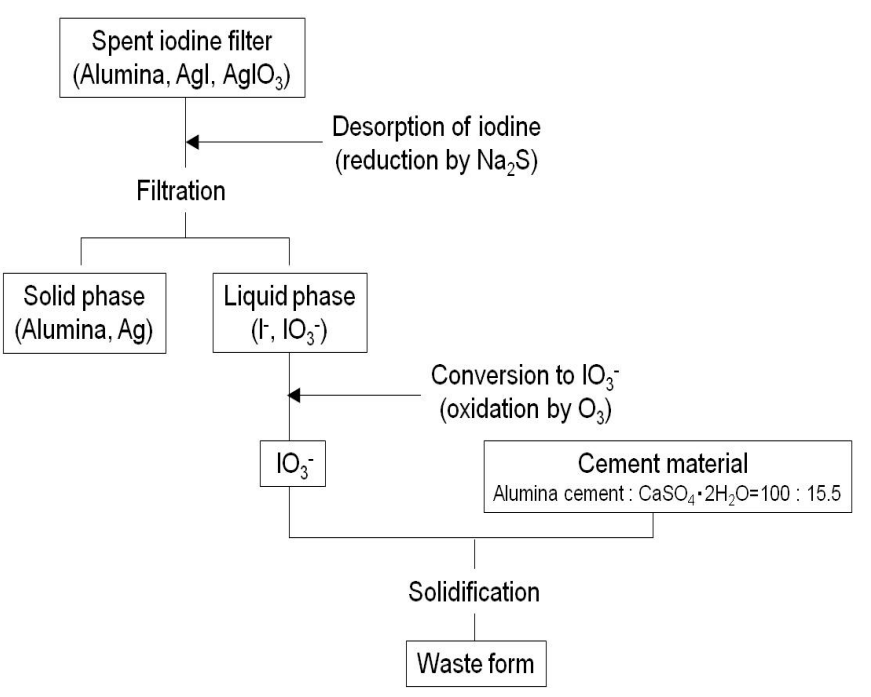

Fig. 6 High-performance cement solidification process for I-129 conventional cement. To scale up the cement solidification process, $20 \mathrm{~L}$ of the solidified substance was manufactured using the established ratios, then the homogeneity and quality of outward appearance were confirmed. Table 4 shows the mineral composition of the cement solid and the corresponding iodine fractions. The table shows that iodine is present in AFt and AFm, which account for approximately $80 \%$ and $6 \%$ of the total iodine. In addition, the presence of iodine in the minerals containing calcium, aluminum and sulphur was confirmed by applying SEM-EDS techniques to the solid form.

In order to evaluate the iodine immobilization capability of the cement solid, accelerated dissolution tests were conducted by a repeated replacement with an ion-exchanged water as the immersing fluid. Fig. 7 shows the concentrations of cementitious elements as a function of the overall liquid-to-solid ratio $(\mathrm{L} / \mathrm{S})$. The results show that the iodine concentration after the alteration of the solid is in an acceptably low range. In addition, AFt remained in the altered cement solid after replacement with ion-exchanged water.

Based upon these findings, we believe that $\mathrm{IO}_{3}{ }^{-}$is immobilized in the cement solid by transfer through ion-exchange substitution to the anion site of cementitious minerals, especially AFt, and that iodine may be released from the cement solid if $\mathrm{AFt}$ that has undergone $\mathrm{IO}_{3}{ }^{-}$substitution is dissolved. Therefore, the iodine release from this cement solid may be evaluated by the solubility equilibrium model, which is based on the concept that the solubility of cementitious minerals is 
affected by the chemical properties of groundwater. The alteration of minerals in the cement and the release of iodine due to immersion were evaluated in thermo-equilibrium conditions by using the PHREEQC Interactive v2.155 [7]. The initial composition of the minerals is listed in Table 4 and the chemical properties of groundwater were estimated based on a fresh groundwater.

Calculations using the PHREEQC model revealed that iodine concentration released from the cement solid on the order of $10^{-5} \mathrm{~mol} / \mathrm{L}$ for lower $\mathrm{L} / \mathrm{S}$ values and less than or equal to $10^{-3} \mathrm{~mol} / \mathrm{L}$ at higher $\mathrm{L} / \mathrm{S}$ values. In addition, the model suggests that $\mathrm{AFt}$ that has undergone $\mathrm{IO}_{3}{ }^{-}$substitution will remain in the cement solid for conditions up to $L / S=500$. According to a simulation of disposal conditions described in the TRU report [2], the $\mathrm{L} / \mathrm{S}=500$ condition may be equivalent to an elapsed time of $10^{5}$ years or more after disposal. Therefore, it is believed that the cement solid retains its iodine confinement ability for as long as $10^{5}$ years.

Table 3 Physical properties of cement solidified substance

\begin{tabular}{|l|l||l|}
\hline \multirow{2}{*}{ Mixing properties } & Mlow value [cm] & \multicolumn{1}{c|}{ Values } \\
\cline { 2 - 3 } & P funnel value [sec.] & $29.2,27.8$ \\
\cline { 2 - 3 } & Coefficient of viscosity [dPa $\cdot \mathrm{s}]$ & $12.2,12.7$ \\
\hline \multirow{4}{*}{ Hardening properties } & Hardening time [min] & Initial setting: 45, final setting: 120 \\
\cline { 2 - 3 } & Bleed [\%] & After 3 hrs: 0 \\
& & Over 20 hrs: 0 \\
\cline { 2 - 3 } & Coefficient of expansion [\%] & $0.35 \%$ \\
\hline \multirow{3}{*}{$\begin{array}{c}\text { Characteristics of } \\
\text { cemt solid }\end{array}$} & Axial compression strength [MPa] & After 30 days: 22 \\
\cline { 2 - 3 } & Density [g/cm ${ }^{3}$ ] & 1.74 \\
\cline { 2 - 3 } & Porosity [\%] & 30 \\
\cline { 2 - 3 } & Iodine content [\%] & 1.7 \\
\cline { 2 - 3 } & External appearance & Good (no cracks) \\
\hline
\end{tabular}

* Test pieces: diameter $=5 \mathrm{~cm}$, height $=10 \mathrm{~cm}$

Table 4 Mineral composition of cement solid and iodine fraction

\begin{tabular}{|l||c|c|c|c|c|c|}
\hline \multicolumn{1}{|c|}{ Minerals } & $\begin{array}{c}\text { Ettringite } \\
(\mathrm{AFt})\end{array}$ & $\begin{array}{c}\text { Monosulfate } \\
(\mathrm{AFm})\end{array}$ & Hydrogarnet & Calcite & $\begin{array}{c}\text { Monocalcium } \\
\text { aluminate }\end{array}$ & Gibbsite \\
\hline \hline Composition [\%] & 12 & 23 & 19 & 0 & 2 & 45 \\
\hline Iodine fraction [\%] & 79 & 6 & 16 & 0 & 0 & 0 \\
\hline
\end{tabular}
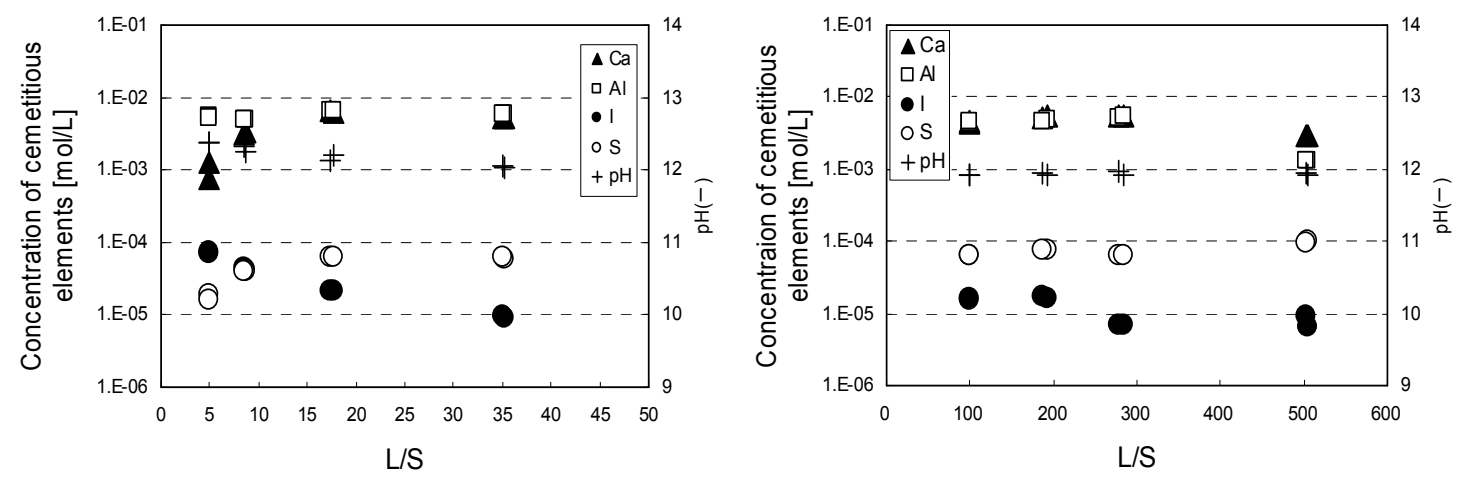

Fig. 7 Concentrations of cementitious elements as a function of overall liquid-to-solid ratio (L/S) 
BPI vitrification technique [10-13].

Outline and principle. The BPI vitrification technique consists of an iodine recovery from a spent iodine filter using $\mathrm{H}_{2}$ and a low-temperature vitrification to form a homogeneous dispersion of iodine in a $\mathrm{PbO}-\mathrm{B}_{2} \mathrm{O}_{3}-\mathrm{ZnO}$ glass system.

Process flow and conditions. Initially, iodine is desorbed as HI from a spent iodine filter using $\mathrm{H}_{2}$. Then the iodide ion is fixed within $\mathrm{BiPbO}_{2} \mathrm{I}$ (BPI) by reaction with an inorganic anion exchanger, $\mathrm{BiPbO}_{2} \mathrm{NO}_{3}(\mathrm{BPN})$. The ion exchange reaction can be described as follows:

$$
\mathrm{BiPbO}_{2} \mathrm{NO}_{3}+\mathrm{I}^{-} \rightarrow \mathrm{BiPbO}_{2} \mathrm{I}+\mathrm{NO}_{3}^{-}
$$

The vitrification process uses a low melting temperature of $813 \mathrm{~K}$ to avoid an iodine volatilization during the vitrification with $\mathrm{PbO}-\mathrm{B}_{2} \mathrm{O}_{3}-\mathrm{ZnO}$ glass frit (Fig. 8).

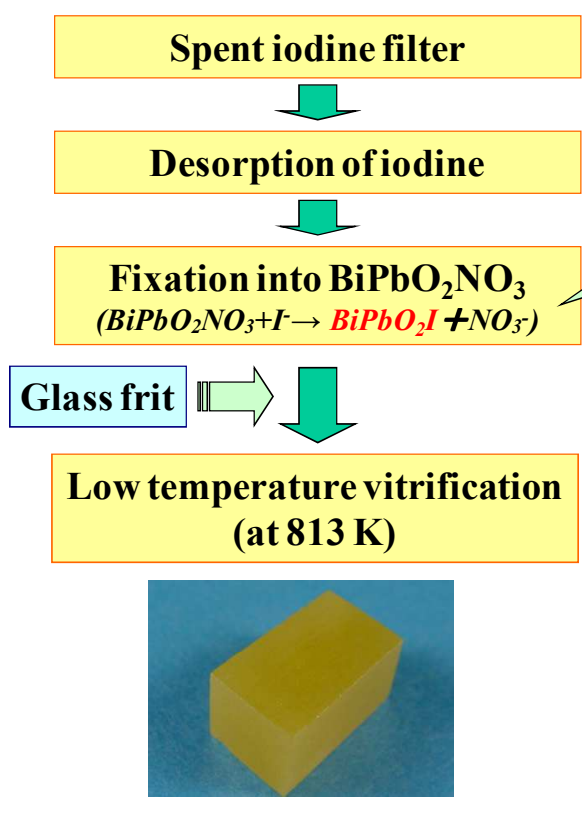

BPI Vitrified waste

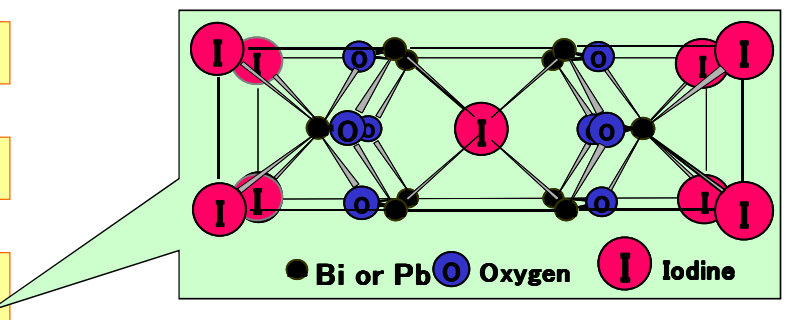

Structure of $\mathrm{BiPbO}_{2} \mathrm{I}$

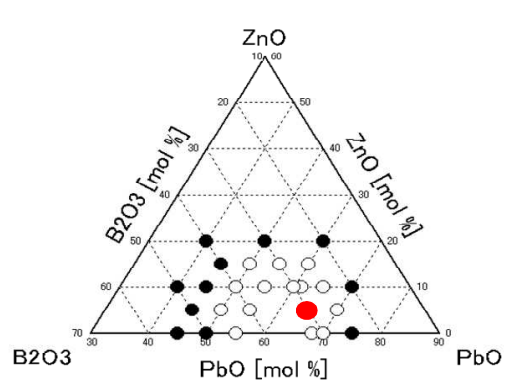

Composition of $\mathrm{PbO}-\mathrm{B}_{2} \mathrm{O}_{3}-\mathrm{ZnO}$ glass frit

Fig. 8 Outline of BPI vitrification process

Characteristics of solidified substance. To advance the understanding of the BPI glass, its microstructure was analyzed by ${ }^{11} \mathrm{~B}$ MAS-NMR, XRD, XPS and XAFS. Based on ${ }^{11} \mathrm{~B}$ NMR spectrums of the $\mathrm{PbO}-\mathrm{B}_{2} \mathrm{O}_{3}$-based glasses with iodine contents for $0.2,1.0$, and $2.0 \mathrm{wt} \%$, the ratio of tri-coordinated boron (B3) and tetra-coordinated boron (B4) was approximately 7:3. The RDF curves obtained by XRD analysis of the above glasses using SPring-8 (Super Photon ring-8GeV) are similar, which suggests that these glasses have nearly the same bulk structure. In addition, peaks can be found at $0.24 \mathrm{~nm}$ and $0.39 \mathrm{~nm}$, which represent the $\mathrm{Pb}-\mathrm{O}$ bond and the $\mathrm{Pb}-\mathrm{Pb}$ pair, respectively. XPS and XAFS analyses show that iodine is present in the BPI glass in the iodide ion 
state and selectively forms $\mathrm{Pb}$-I bonds, and that the microstructures surrounding the iodine in the glass matrix are nearly the same.

To demonstrate the feasibility of the BPI vitrification process, a prototype melting furnace was developed to produce the BPI vitrified waste in quantities of $0.5 \mathrm{~L}$. The samples were divided into 90 pieces and underwent XRD analysis, which found the samples to be amorphous. The dispersion of iodine contents and the specific gravity in the samples was small enough to be considered homogeneous. The uniaxial compressive strength of the BPI glass was over $40.8 \mathrm{MPa}$. The volatilization rates of iodine during the BPI vitrification were found to be in the range of 5-6\%.

Leaching tests were conducted to evaluate the iodine leaching rate from the BPI vitrified waste in various solutions that simulated geological disposal conditions. Table 5 and Fig. 9 show the experimental conditions for the leaching tests and normalized leaching rates of boron $\left(\mathrm{NL}_{\mathrm{B}}\right)$ and iodine $\left(\mathrm{NL}_{\mathrm{I}}\right)$ that resulted.

Table 5 Experimental conditions for leaching tests

\begin{tabular}{|c|c|c|}
\hline & Item & Contents \\
\hline \multicolumn{2}{|c|}{ Ratio of liquid/solid } & $10 \mathrm{~mL} / \mathrm{g}$ \\
\hline Solid & Glass & BPI glass, $\quad 10 \mathrm{~mm} \times 20 \mathrm{~mm} \times 5 \mathrm{~mm}(7 \mathrm{~g})$ \\
\hline \multirow{3}{*}{ Liquid } & Leachant & $\begin{array}{l}\text { 1) } \mathrm{Ca}(\mathrm{OH})_{2} \text { solution }(\mathrm{pH} 9) \\
\text { 2) } 0.55 \mathrm{M} \mathrm{NaCl}+0.05 \mathrm{M} \mathrm{NaHCO}{ }_{3} \text { solution } \\
\text { 3) Bentonite-equilibrium water }\end{array}$ \\
\hline & Temperature & Room temperature \\
\hline & Reductant & Electrolytic iron powder (1 wt \%) \\
\hline \multicolumn{2}{|c|}{ Atmosphere } & Low oxygen (less than 1 ppm) \\
\hline
\end{tabular}
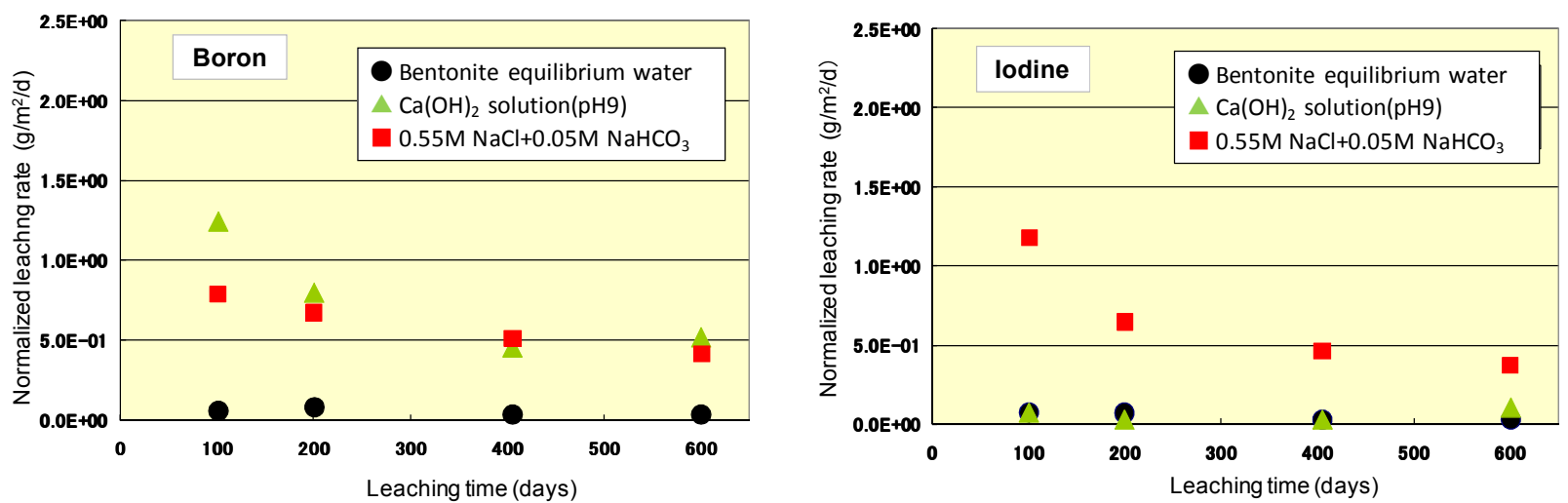

Fig. 9 Normalized leaching rate of boron and iodine

Fig. 10 shows the conceptual model of the iodine dissolution from the BPI glass. The dissolution behavior can be categorized into two types depending on the properties of the solution used. One type of behavior is that iodine dissolves congruently with boron, which indicates the dissolution of the glass matrix. This behavior can be observed in a bentonite equilibrated water, a $\mathrm{NaCl}$ solution, and similar media. The other type of behavior is that iodine dissolves quite slowly 
compared to boron. This behavior can be observed in a $\mathrm{Ca}(\mathrm{OH})_{2}$ solution.

When iodine dissolved congruently with boron, an altered layer was observed at the glass surface. Also, both boron and iodine were depleted in the altered layer. These observations suggest that the glass dissolution rate is related the formation rate of the altered layer. Moreover, the dissolution rate of boron and iodine was proportional to time $t^{0.5}$, which suggests that diffusion occurs.

In the other case, in which iodine does not dissolve congruently with boron, a precipitation layer was observed in addition to the altered layer. An EPMA analysis showed significant concentrations of iodine and bismuth in the precipitation layer, and a XANES analysis suggested that a compound similar to a BPI crystal was precipitated. The iodine dissolution rate appears to be controlled by the extent of immobilization in the precipitation layer.

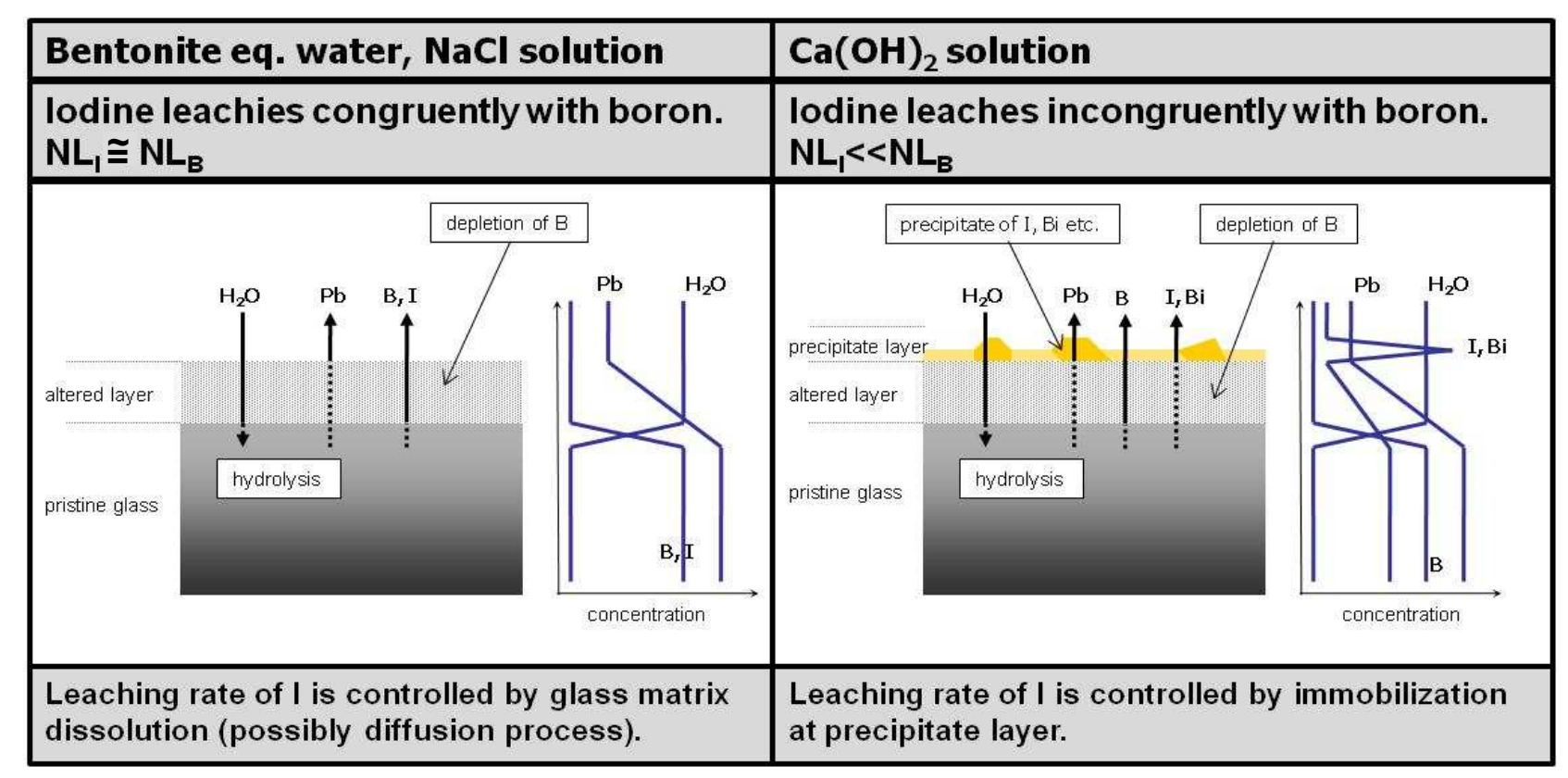

Fig. 10 Conceptual model of iodine dissolution behavior from BPI vitrified waste

\section{Summary}

This report presented developments and results of I-129 immobilization techniques. Several alternative techniques were proposed and, after the preliminary study and evaluation, three candidate techniques are now under study. Although each technique demonstrates a potential to achieve the long-term I-129 confinement objective by a solidified substance, each technique shows its own specific features as well. Synthetic rock may demonstrate the superior confinement performance in a neutral $\mathrm{pH}$, fresh groundwater environment, where alumina matrix solubility is low. High-performance cement can be used for all types of groundwater with the exception of a saline groundwater where accelerated matrix dissolution makes it difficult to achieve the confinement objective. BPI glass has a simple modified layer in a bentonite-equilibrium water 
environment or a saline groundwater environment that dissolves congruently with boron. However, BPI glass will form a complex modified layer on its surface when immersed in a groundwater environment that is influenced by the leaching of calcium from cement materials.

Future research will focus on long-term immersion tests to develop the evaluation model of long-term performance of each solidified substance under a variety of groundwater conditions. The research to evaluate treatment feasibility by obtaining the basic process data for achieving an I-129 recovery rate of $95 \%$ or greater will be also pursued.

\section{Acknowledgements}

This research is a part of "Research and development of processing and disposal technique for TRU waste containing I-129 and C-14" program funded by the Ministry of Economy, Trade and Industry (METI).

\section{References}

[1] Japan Nuclear Cycle Development Institute and the Federation of Electric Power Companies: Progress Report on Disposal Concept for TRU Waste in Japan (2000).

[2] Japan Nuclear Fuel Cycle Development Institute and the Federation of Electric Power Companies: Progress Report on Disposal technology for TRU Waste in Japan (2005) (in Japanese).

[3] R.Wada, T.Nishimura et al. in: Fixation Radioactive Iodine by Hot Isostatic Pressing, ICEM 1999t, Session 35(L-7), No.20 (1999).

[4] R.Wada, T.Nishimura et al.: Manufacturing of Rock Solidified Waste by HIP, A publication of the Atomic Energy Society of Japan, 3 [2], 165-173 (2004) (In Japanese).

[5] R.Wada, T.Nishimura et al.: Study on Iodine-Leaching Mechanism for HIP Rock Solidified Waste Form, A publication of the Atomic Energy Society of Japan, 3[2], 174-184 (2004) (in Japanese).

[6] Yaohiro INAGAKI, Toshitaka IMAMURA, et al: Aqueous Dissolution of Silver Iodine and Associated Iodine Release under Reducing Conditions with $\mathrm{FeCl}_{2}$ Solution, Journal of Nuclear Science and Technology, Vol.45, No.9, p.859-866 (2008).

[7] D. L. Parkhurst and C. A. J. Apple, "User's Guide to PHREEQC (VERSION2), US. Geological Survey (1999).

[8] F. Tomita, K. Kaneko et al.: Development of Iodine Immobilization Process with Cementitious Materials, ICEM 1999 (1999).

[9] M. Toyohara, M. Kaneko et al.: Iodine Sorption onto Mixed Solid Alumina Cement and Calcium Compounds, Journal of Nuclear Science and Technology, Vol.37, No.11, p970 (2000).

[10] T. Amaya, A. Mukunoki and M. Shibuya: Study of $\mathrm{BiPbO}_{2} \mathrm{NO}_{3}$ for I-129 Fixation under Reducing Conditions, MRS 2000 (2000). 
[11] T. Amaya, A. Mukunoki, M. Shibuya and H. Kodama: Leaching of Iodine Ion from $\mathrm{BiPbO}_{2} \mathrm{I}$ under Reducing Conditions, ICEM 2001 (2001).

[12] A. Mukunoki, T. Chiba: Development of an Iodine Immobilization Technique by Low Temperature Vitrification with $\mathrm{BiPbO}_{2} \mathrm{I}$, ICEM07-7142 (2007).

[13] A. Mukunoki, T. Chiba, Y. Suzuki: Further Development of Iodine Immobilization Technique by Low Temperature Vitrification with $\mathrm{BiPbO}_{2} \mathrm{I}$, ICEM2009-16268 (2009). 